\title{
A short-term rural placement can change metropolitan medical students' knowledge of, and attitudes to, rural practice
}

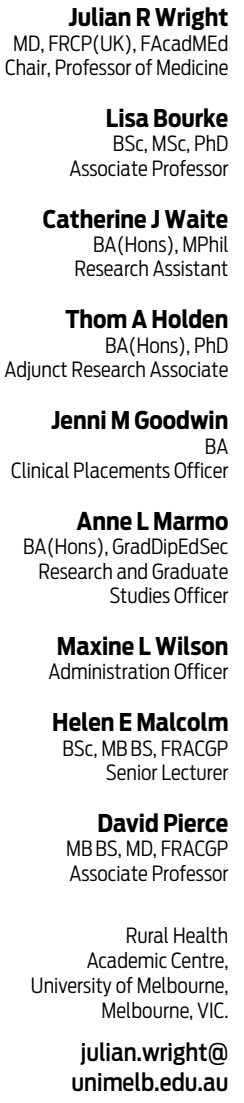

MJA 2014; 201: 103-105 doi: $10.5694 /$ mjal3.11329 nitiatives to address rural and remote health workforce shortages in Australia ${ }^{1}$ have resulted in a large number of international medical graduates working in rural Australia, often with low job satisfaction. ${ }^{2}$ Students from a rural background are more likely to choose a rural career than their colleagues from urban backgrounds. ${ }^{3-6}$ Efforts to reduce the rural workforce deficit in Australia include the Rural Clinical School (RCS) program. Similar initiatives are in place in Canada and the United States. ${ }^{7}$

Early indications are that the RCS program has a positive influence on rural career choice. ${ }^{8,9}$ The Mason Review of Australian Government health workforce programs recommended that the requirement for all Commonwealthsupported Australian medical students to undergo a minimum of 4 weeks of rural training be abolished in favour of longer placements ${ }^{10}$ which, together with a rural background, would lead to improved medical workforce outcomes. ${ }^{11}$

Medical students require an understanding of rural practice, which presents different challenges to urban medicine. ${ }^{12}$ An experience of rural medicine is a factor in choosing careers in rural health, and improves access to medical care for rural communities. ${ }^{13}$ Since 2004, all University of Melbourne medical students have undertaken a compulsory Rural Health Module (RHM) run by the Rural Health Academic Centre. The RHM includes a 2-day orientation (Appendix 1; all appendices online at mja.com.au), an 11-day rural clinical or community placement and a concluding placement presentation day. In this study, we sought to establish if the short-term RHM changes medical students' knowledge of and attitudes to rural issues.

\section{Methods}

Ethics approval for this evaluation was obtained from the University of Melbourne Human Research Ethics

\section{Abstract}

Objective: To determine whether a short-term placement of metropolitan medical students in a rural environment can improve their knowledge of, and change their attitudes to, rural health issues.

Design and participants: Medical students taking part in the March and May 2013 3-week Rural Health Modules (RHMs) were invited to participate in focus groups and complete questionnaires before undertaking the RHM, after a 2-day rural orientation and at the end of the RHM. Students were asked to comment on a range of issues affecting rural health care including their attitude to pursuing a rural career. Focus group transcripts were thematically analysed and questionnaire data were statistically analysed.

Setting: The RHM is a 3-week program designed and run by the University of Melbourne's Rural Health Academic Centre.

Main outcome measures: Responses to questionnaire items from before and after completing the RHM, scored on a seven-point Likert scale.

Results: 69 of the 101 RHM students took part in this study. The focus groups identified five main themes in rural health care: access; teamwork, models of care and generalist practice; overlapping relationships; indigenous health; and working in a rural career. In all five areas, a change was seen in the depth of knowledge students had about these issues and in the students' attitudes towards rural health care. The questionnaires also showed a significant shift in the students' appreciation of, and positivity towards, rural health issues.

Conclusion: Undertaking a 3-week RHM changed students' perceptions of rural health and improved their knowledge of issues facing rural health practitioners and patients.

Committee. Students taking part in the March and May 2013 3-week RHMs were asked to participate in a focus group and complete a short questionnaire at the beginning and conclusion of the orientation, and on the final day of the RHM. Focus group facilitators used the same set of questions (Appendix 2) but adapted and probed for more detail, where appropriate, as consistent with semistructured interviewing approaches. ${ }^{14}$

Focus groups were recorded and transcribed for analysis. Two of us independently read the transcripts and agreed on themes that reflected the common ideas of participants and/or a change in knowledge of, or attitudes to, rural health issues during the RHM experience. The same two researchers then re-read transcripts independently to thematically code all the data. ${ }^{15}$

Questionnaires focused on topics covered in the orientation and investigated attitudes to rural practice. Responses were scored using a seven-point Likert scale with " 1 " denoting a response of strong disagreement and " 7 " denoting strong agreement. Questionnaire data were described in terms of mean question scores. Data were analysed using paired sample $t$ tests.

\section{Results}

A total of 101 medical students, who were all based in metropolitan clinical schools, completed the RHM. Of these 101 students, data on place of origin were collected for 91 (90.1\%). Five students were of rural origin. Most (68\%) of the RHM students took part in the research: 69 medical students took part in the first focus group and questionnaire, 50 took part in the second and 54 took part in the third.

\section{Focus group analysis}

Findings from the focus groups fell under five themes identified by the students. 
Students' responses to questionnaire items before and after completing the Rural Health Module (RHM)

\begin{tabular}{|c|c|c|c|}
\hline \multirow[b]{2}{*}{ Questionnaire item } & \multicolumn{2}{|c|}{ Mean response score* } & \multirow[b]{2}{*}{$P$} \\
\hline & $\begin{array}{l}\text { Before RHM } \\
\quad( \pm \text { SD })\end{array}$ & $\begin{array}{l}\text { After RHM } \\
\quad( \pm \text { SD })\end{array}$ & \\
\hline I am confident in my knowledge of rural health & $3.4( \pm 1.4)$ & $5.3( \pm 0.9)$ & $<0.001$ \\
\hline It is easy to learn about rural health & $4.0( \pm 1.2)$ & $4.4( \pm 1.3)$ & 0.010 \\
\hline $\begin{array}{l}\text { The advantages of working in rural areas } \\
\text { outweigh the disadvantages }\end{array}$ & $3.5( \pm 1.2)$ & $4.2( \pm 1.1)$ & $<0.001$ \\
\hline $\begin{array}{l}\text { There are career advantages to working in } \\
\text { rural areas }\end{array}$ & $4.6( \pm 1.3)$ & $4.7( \pm 1.3)$ & 0.51 \\
\hline $\begin{array}{l}\text { I am confident I could work in a rural health } \\
\text { service }\end{array}$ & $3.7( \pm 1.5)$ & $5.3( \pm 0.9)$ & $<0.001$ \\
\hline $\begin{array}{l}\text { I am confident I could work in an Aboriginal } \\
\text { health service }\end{array}$ & $2.9( \pm 1.6)$ & $3.6( \pm 1.5)$ & $<0.001$ \\
\hline $\begin{array}{l}\text { I am not confident in my knowledge of Aboriginal } \\
\text { health }\end{array}$ & $5.3( \pm 1.4)$ & $4.3( \pm 1.6)$ & 0.013 \\
\hline $\begin{array}{l}\text { Personal and professional boundaries are more } \\
\text { difficult for rural doctors to maintain than for } \\
\text { regional doctors }\end{array}$ & $5.2( \pm 0.9)$ & $5.9( \pm 0.9)$ & $<0.001$ \\
\hline I would like to work in a rural environment & $3.8( \pm 1.4)$ & $4.4( \pm 1.4)$ & $<0.001$ \\
\hline $\begin{array}{l}\text { There are lifestyle advantages to working in } \\
\text { rural areas }\end{array}$ & $4.7( \pm 1.3)$ & $4.9( \pm 1.1)$ & 0.10 \\
\hline $\begin{array}{l}\text { Working as a rural doctor is more complex than } \\
\text { working as a regional doctor }\end{array}$ & $4.9( \pm 1.1)$ & $5.1( \pm 1.0)$ & 0.36 \\
\hline $\begin{array}{l}\text { Rural doctors have more professional autonomy } \\
\text { than regional doctors }\end{array}$ & $4.7( \pm 0.9)$ & $5.2( \pm 1.0)$ & 0.001 \\
\hline $\begin{array}{l}\text { Working in a rural health setting is different to } \\
\text { working in a regional setting }\end{array}$ & $2.4( \pm 1.1)$ & $2.4( \pm 1.0)$ & 0.62 \\
\hline $\begin{array}{l}\text { I am familiar with the complexities of working in } \\
\text { a rural environment }\end{array}$ & $3.8( \pm 1.5)$ & $5.3( \pm 0.9)$ & $<0.001$ \\
\hline $\begin{array}{l}\text { A rural doctor works more closely with the local } \\
\text { community than a regional one }\end{array}$ & $5.4( \pm 1.1)$ & $5.9( \pm 1.0)$ & 0.004 \\
\hline Most rural practice is primary health care & $5.1( \pm 0.9)$ & $5.7( \pm 1.1)$ & 0.003 \\
\hline $\begin{array}{l}\text { Most of what I know about rural practice I learned } \\
\text { in my medical course on my RHM placement }\end{array}$ & $5.7( \pm 1.5)$ & $4.8( \pm 1.5)$ & 0.68 \\
\hline
\end{tabular}

* Responses are scored on a seven-point Likert scale of 1 to 7 ( 1 = strongly disagree, 4 = neither agree nor disagree, $7=$ strongly agree).

Access. Access to health care was identified as a major issue. Distance to larger centres posed a challenge to both practitioners and patients: "...a lot of [rural] people require transport into metropolitan areas and it might be a bit difficult sometimes". As students progressed through the RHM, their "... understanding of access... expanded a little bit, it includes things like affordability which I didn't really think about. In the country, things are a lot more expensive for people".

Many students initially noted that small towns lacked amenities and felt this was a disincentive to working in rural health: "It is not just the hospital, but petrol. You can't get petrol on Saturday or Sunday... they close down at $5 \mathrm{pm}$ on Friday and you can't get petrol till Monday. I would always be running out of petrol". Another stated, "There is seriously nothing to do in town, like everything was closing by 5 [pm]".

Teamwork, models of care and generalist practice. Initially, students perceived rural doctors as providing generalist care with little collegial support. Students thought rural doctors were isolated from specialists, working alone with little social support. In the final focus groups, students commented on how much teamwork they had seen during their placements. Some were surprised at how much a general practitioner has to do but also at the support of other staff and how models of care supported teamwork and quality of care. Talking about their placements, students indicated important learnings about interprofessional teamwork, models of care and generalism. "I think it really had better patient outcomes because it was so unified."
Overlapping relationships. Initially, students spoke tentatively about the practical implications of "everybody knowing everybody else" in small communities: "You would be friends with your patients and that would be a conflict of interest". Over the RHM, students achieved more understanding of the challenges and opportunities overlapping relationships pose. On the one hand, students suggested that awkward social situations could occur, "... [the doctors] would go home for lunch and people would come in the back door and be like, 'Hey I am feeling sick'. Because they were like 'I know you so well, we are friends', and the doctor is like, 'We are not really friends, I just know you really well' ". On the other hand, students also recognised that the detailed knowledge doctors had about their patients enabled them to provide more holistic health care. Students felt this was a contrast with metropolitan clinics where emphasis was more on patient throughput: "I was just staggered at how much information he had in terms of their personal history. You got a completely different perspective on this patient".

Indigenous health. Few RHM placements were based in Aboriginal health; a Cultural Safety day was held as part of the orientation by an Indigenous team. One student summed up this day saying, "I didn't feel so conscious of my own skin until I went to yesterday's Aboriginal talk". Another stated, "I was just wondering why it is that we are never exposed to [this] ... I am just wondering why you are making all these points now when it was pretty much abandoned for the first 5 years of our [course] ... It is so important". Students who undertook a placement in Aboriginal health were more likely to understand Aboriginal health and the concepts of cultural safety and cultural security, "... because you can hear about it theoretically ... but when you sort of see the doctors having to deal with it, and you see the patients that are walking in and walking out... it really brings it home".

Working in a rural career. Initially, many students assumed that rural careers would be an unpopular choice. "I don't think anyone, unless they came from a rural setting, is interested in working in a rural [area] ..." A few students were more open to a rural career: 
"I feel like as a doctor it would be quite professionally rewarding to work rurally". Thoughts about a rural career were mainly about lifestyle and lack of medical specialist opportunities.

By the end of the RHM, students were more positive about a rural career. "... I think a GP in a small rural town could be fun." "I am more positive now, it seems nice working in the country, you know people... you have autonomy in your practice." To others, some aspects of rural health care did not appeal: "I am not a big fan of seeing your patients outside of clinics". Many considered spending some career time in a rural environment. "I think most of us see it as a temporary thing..." Almost all students agreed that they had to experience a rural placement to understand the issues of rural practice.

\section{Questionnaire data}

Students' responses (Box) suggested a positive attitudinal change during the RHM to working in rural areas, with questions about rural health knowledge, working in a rural health service and wanting to work in a rural environment all showing significant changes. Significant changes also occurred in more clearly identifying the enhanced level of professional autonomy, the close community role and the difficulty of overlapping relationships that rural doctors may experience. The positive changes in attitude to rural practice were reported in the context of recognising more strongly the complexities of the rural health care environment. While all students received information about Aboriginal health care, most did not experience an Aboriginal health care placement. Students reported a significant change in their confidence to work in such a setting.

There were differing opinions among the students as to the reasons they would or would not wish to work in a rural setting (Appendix 3 and Appendix 4). A similar percentage of students noted lifestyle advantages and disadvantages in their top four reasons at the beginning of the RHM. It was noticeable that at the end of the RHM a higher percentage of students noted lifestyle advantages and community engagement in their perceived reasons for why they would like to work in a rural environment.
Separation from metropolitan friends and family was a consistent reason against working in a rural environment. The other consistent reason students gave for not wishing to work in a rural environment was the lack of training opportunities and career development.

There was a significant difference between student responses in the first and final questionnaires to the statement, "I would like to work in a rural environment" (posed in an alternative format to the item listed in the Box). All six students who indicated "yes" initially confirmed their desire to work in a rural environment by answering "yes" on the final questionnaire. Of the 36 students who indicated "maybe" initially, 26 answered "maybe" again on the final questionnaire, and eight responded "yes", while two indicated "no". Twelve students answered "no" initially; however, after returning from their placements, nine indicated "maybe", one "yes", and two answered "no" again. Therefore, those indicating a desire to work in a rural environment remained positive throughout the RHM. Additionally, most students indicating "no" or "maybe" at the outset were more open to working rurally after participating in the RHM.

\section{Discussion}

Evidence to date suggests that the longer the rural placement, the more likely that the graduating student will choose a rural career pathway. ${ }^{11}$ However, this evaluation of the RHM suggests that there are benefits to be gained from short-term rural placements incorporating formal rural health teaching in terms of knowledge of and attitudes to rural health issues.

There was an improvement in students' knowledge of the rural issues of access, overlapping relationships, and teamwork, models of care and generalist practice, as a result of completing the RHM. Students appreciated the gaps in their previous knowledge of Aboriginal health issues and also changed their attitude to the possibility of a rural career in the future. These results, seen after the 3-week RHM, show that there remains a place for short-term rural placements. Whether positive change in attitudes to rural health issues continues, resulting in students being more likely to pursue a career in rural health, remains untested.

A limitation of this evaluation is that it only examines one short-term RHM in one geographical location. A second limitation of this study is that only a small sample of 50 students completed all of the focus groups and questionnaires; over 9 years about 2850 students have completed the RHM. Finally, although students' participation in this study was voluntary, completing the RHM was a compulsory part of their curriculum. Different results may have emerged from students motivated to complete the RHM by a personal desire to learn more about rural health. It has been suggested that longer placement times are required to influence student career choices, ${ }^{11}$ but the optimal time of exposure to a rural environment to influence students' career choices remains unknown.

Acknowledgements: We wish to acknowledge the support of the Australian Government through the University Departments of Rural Health and Rural Clinical Training and Support programs.

Competing interests: No relevant disclosures.

Received 20 Oct 2013, accepted 28 Jan 2014.

1 Rourke JT, Strasser R. Education for rural practice in Canada and Australia. Acad Med 1996; 71: 464-469.

2 McGrail MR, Humphreys JS, Joyce CM, Scott A. International medical graduates mandated to practice in rural Australia are highly unsatisfied: results from a national survey of doctors. Health Policy 2012; 108: 133-139.

3 Dunbabin JS, Levitt L. Rural origin and rural medical exposure: their impact on the rural and remote medical workforce in Australia. Rural Remote Health [internet] 2003; 3: 212. Epub 2003 Jun 25.

4 Laven GA, Belby JJ, McElroy HJ, Wilkinson D. Factors associated with rural practice among Australian-trained general practitioners. Med J Aust 2003; 179: 75-79.

5 Wilkinson D, Laven G, Pratt N, Beilby J. Impact of undergraduate and postgraduate rural training, and medical school entry criteria on rural practice among Australian general practitioners: national study of 2414 doctors. Med Educ 2003; 37: 809-814.

6 Rourke JT, Incitti F, Rourke LL, Kennard M. Relationship between practice location of Ontario family physicians and their rural background or amount of rural medical education experience. Can J Rural Med 2005; 10: 231-240.

7 Tesson G, Curran V, Pong R, Strasser R. Advances in rural medical education in three countries: Canada, the United States and Australia. Educ Health (Abingdon) 2005; 18: 405-415.

8 Eley DS, Baker PG. Will Australian rural clinical schools be an effective workforce strategy? Early indications of their positive effect on intern choice and rural career interest. Med J Aust 2007; 187: 166-167.

9 Wilkinson D, Birks J, Davies L, et al. Preliminary evidence from Queensland that rural clinical schools have a positive impact on rural intern choices. Rural Remote Health [internet] 2004; 4: 340. Epub 2004 Dec 6.

10 Mason J. Review of Australian Government health workforce programs. Commonwealth Department of Health and Ageing, 2013. http://www. health.gov.au/internet/publications/publishing.nsf/Content/work-reviewaustralian-government-health-workforce-programs-toc (accessed Oct 2013).

11 Playford DE, Cheong E. Rural Undergraduate Support and Coordination, Rural Clinical School, and Rural Australian Medical Undergraduate Scholarship: rural undergraduate initiatives and subsequent rural medical workforce. Aust Health Rev 2012; 36: 301-307.

12 Bourke L, Sheridan C, Russel U, et al. Developing a conceptual model of rural health practice. Aust J Rural Health 2004; 12: 181-186.

13 Worley P, Murray R. Social accountability in medical education-an Australian rural and remote perspective. Med Teach 2011: 33: 654-658.

14 Minichiello V, Aroni R, Hays T. In-depth interviewing: principles, techniques, analysis. 3rd ed. Sydney: Pearson Education Australia, 2008.

15 Miles MB, Huberman AM, Saldan J. Qualitative data analysis: a methods sourcebook. 3rd ed. Thousand Oaks, CA: Sage, 2014. 